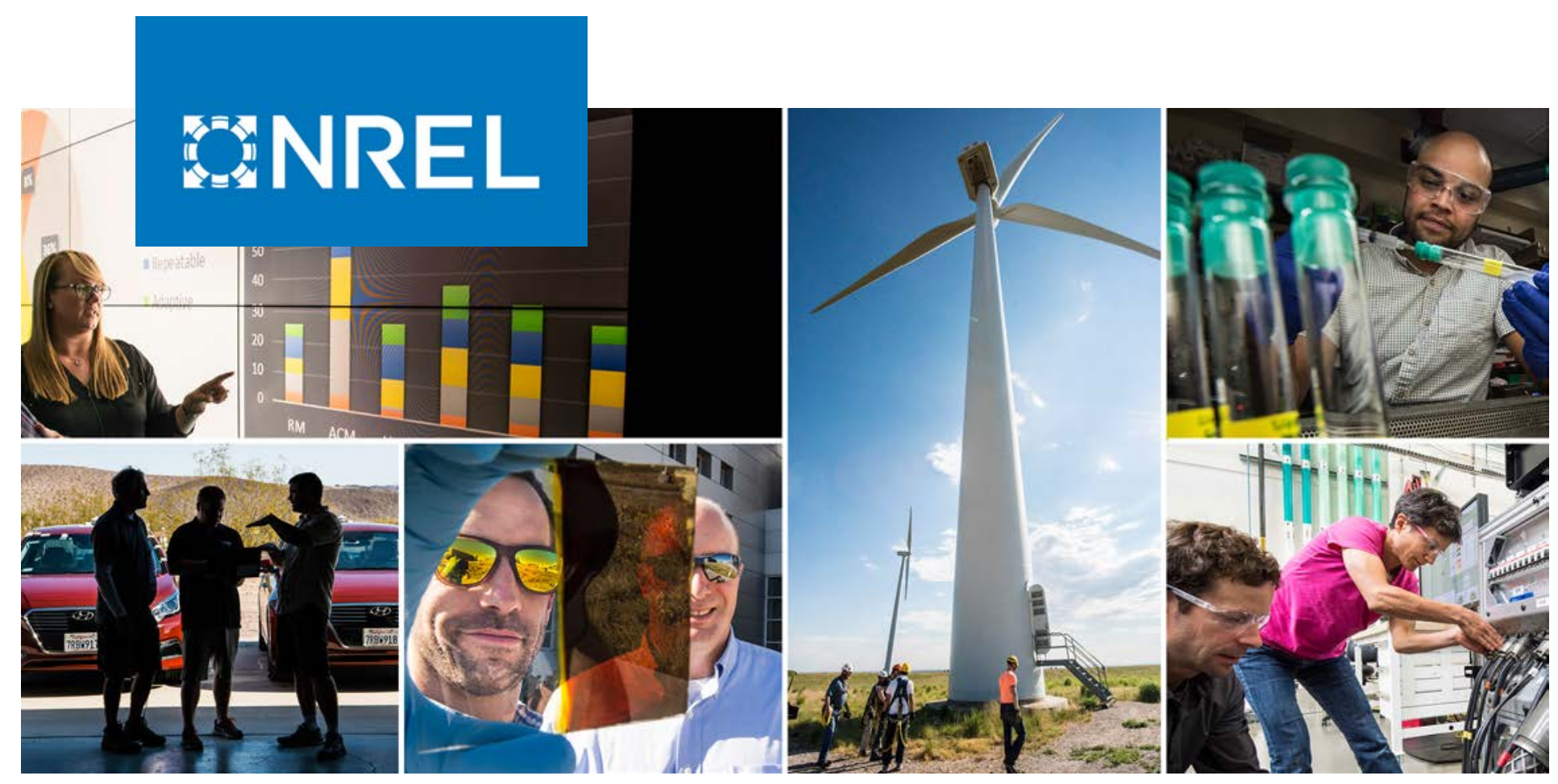

\title{
Research and Testing of Power Use of HPC Workload of Participant's HPC System
}

\section{Cooperative Research and Development Final Report}

CRADA Number: CRD-16-626

NREL Technical Contact: Kevin Regimbal

NREL is a national laboratory of the U.S. Department of Energy Office of Energy Efficiency \& Renewable Energy

Operated by the Alliance for Sustainable Energy, LLC

This report is available at no cost from the National Renewable Energy Laboratory (NREL) at www.nrel.gov/publications.
CRADA Report

NREL/TP-2C00-73293

February 2019 


\section{BNREL}

\section{Research and Testing of Power Use of HPC Workload of Participant's HPC System}

\section{Cooperative Research and Development Final Report}

\section{CRADA Number: CRD-16-626}

NREL Technical Contact: Kevin Regimbal

\section{Suggested Citation}

Regimbal, Kevin. 2019. Research and Testing of Power Use of HPC Workload of Participant's HPC System: Cooperative Research and Development Final Report, CRADA Number CRD-16-626. Golden, CO: National Renewable Energy Laboratory. NREL/TP-5000-73293. https://www.nrel.gov/docs/fy19osti/73293.pdf.

NREL is a national laboratory of the U.S. Department of Energy Office of Energy Efficiency \& Renewable Energy Operated by the Alliance for Sustainable Energy, LLC

This report is available at no cost from the National Renewable Energy Laboratory (NREL) at www.nrel.gov/publications.

Contract No. DE-AC36-08GO28308
CRADA Report

NREL/TP-2C00-73293

February 2019

National Renewable Energy Laboratory 15013 Denver West Parkway Golden, CO 80401 303-275-3000 • www.nrel.gov 


\section{NOTICE}

This work was authored by the National Renewable Energy Laboratory, operated by Alliance for Sustainable Energy, LLC, for the U.S. Department of Energy (DOE) under Contract No. DE-AC36-08GO28308. Funding provided by the U.S. Department of Energy Office of Science (SC), Advanced Scientific Computing Research (ASCR), Scientific Discovery through Advanced Computing (SciDAC). The views expressed herein do not necessarily represent the views of the DOE or the U.S. Government.

This report is available at no cost from the National Renewable Energy Laboratory (NREL) at www.nrel.gov/publications.

U.S. Department of Energy (DOE) reports produced after 1991 and a growing number of pre-1991 documents are available free via www.OSTI.gov.

Cover Photos by Dennis Schroeder: (clockwise, left to right) NREL 51934, NREL 45897, NREL 42160, NREL 45891, NREL 48097, NREL 46526.

NREL prints on paper that contains recycled content. 


\title{
Cooperative Research and Development Final Report
}

\section{$\underline{\text { Report Date: } 10 / 18 / 18}$}

In accordance with requirements set forth in the terms of the CRADA agreement, this document is the final CRADA report, including a list of subject inventions, to be forwarded to the DOE Office of Science and Technical Information as part of the commitment to the public to demonstrate results of federally funded research.

Parties to the Agreement: Colorado School of Mines

CRADA number: CRD-16-626

CRADA Title: Research and Testing of Power Use of HPC Workload of Participant's HPC System Joint Work Statement Funding Table showing DOE commitment:

\begin{tabular}{|c|r|}
\hline Estimated Costs & $\begin{array}{c}\text { NREL Shared Resources } \\
\text { a/k/a Government In-Kind }\end{array}$ \\
\hline Year 1 & $\$ 59,616.00$ \\
Year 2 or Modification \# & $\$ 64,799.00$ \\
Year 3 or Modification \# & $\$ 59,710.00$ \\
Year 4 or Modification \# & $\$ 184,125.00$ \\
\hline TOTALS & \\
\hline
\end{tabular}

\begin{abstract}
CRADA Work:
This CRADA (1) facilitates relocation of the Board of Trustees of the Colorado School of Mines, for and on behalf of the Colorado School of Mines, (MINES or Participant) International Business Machines Corporation (IBM) supercomputing system into the National Renewable Energy Laboratory's (NREL or Contractor) Energy Systems Integration Facility (ESIF). This CRADA (1) facilitates testing High Performance Computing (HPC) application platform portability, scalability, electrical energy use, and performance for applications critical to each organization; (2) facilitates use of the existing facility electrical and thermal data collection systems at Contractor ESIF in support of characterizing HPC workload power use characterization; and (3) facilitates addition of application power use data on the Participant IBM supercomputing system into the Contractor ESIF Time Series data system to use/re-use existing methodology to profile application power use.
\end{abstract}




\section{Summary of Research Results:}

Task 1: Relocation of Participant's IBM supercomputing system to Contractor ESIF HPC Data $\underline{\text { Center. }}$

Contractor Responsibilities:

1. Designate local representatives who shall, on occasion as mutually agreed upon, perform such tasks as power cycling of equipment.

2. In case of an emergency, perform an Emergency Power Outage (EPO) and/or undertake any other action(s) necessary.

3. Maintain the supporting infrastructure needed to operate the computer as described in the CRADA, including providing the floor space, cooling, and other environmental systems necessary for the system while it is located at the ESIF.

4. Provide the same level of physical security, access security, monitoring, and fire protection for the system that is provided for comparable contractor resources housed in the ESIF.

5. Ensure that the system has access and connections to power and back-up power sources consistent with that which is provided for comparable contractor resources housed in the ESIF.

6. Provide reasonable physical access to the system for designated participant and its subcontractors' personnel, including the right to enter the ESIF with reasonable notice and during normal business hours, and use it for the Purpose and for the Term of the CRADA. Contractor agrees to provide participants' designated personnel with badges or other entry devices, as necessary and with reasonable notice.

7. Provide non-proprietary and/or non-confidential information to participant as requested in order for participant to determine that the ESIF infrastructure is adequate to support the system.

8. Provide fiber optic connectivity in the contractor ESIF to the participant provided network device.

9. Provide a pilot project account on Peregrine to a designated participant representative to support the collaborative research described in the Purpose section.

This activity was completed successfully. The IBM supercomputing system was installed in the NREL ESIF HPC data center.

Task 2: Initiate Data Collection

Contractor Responsibilities:

1.Provision data collection from the facilities meters into the ESIF Time Series database.

2.Process CSV files provided by participant to load data into the ESIF Time Series database. 
NREL verified that facility data collection was working as expected.

CSV files were not provided by participant to NREL. Without data from the IBM supercomputing system, Task 3 and Task 4 could not be completed.

Task 3: Data Analysis

Contractor Responsibilities:

1. Apply application power analysis methodology to data from participant's IBM supercomputing system

2. Host collaboration session to look at data to identify important applications and trends

Data analysis task was not completed. CSV files as described in the JWS were not provided to NREL.

Task 4: Reporting

Contractor Responsibilities:

1. Draft report which summarizes methodology, findings, and conclusions.

Reporting task was not completed. CSV files as described in the JWS were not provided to NREL.

The hardware was removed from the ESIF HPC datacenter in January, 2018.

Subject Inventions Listing:

None

ROI \#:

None

Responsible Technical Contact at Alliance/NREL:

Kevin Regimbal

Name and Email Address of POC at Company:

Timothy Kaiser, tkaiser@mines.edu

This document contains NO confidential, protectable, or proprietary information. 